\title{
Paper
}

\section{Anisotropic Mechanical Properties of Ni-base Superalloy Compacts by Direct Laser Forming Technology}

\author{
Naoto YOSHIGAI ${ }^{1}$, Kentaro KUDO ${ }^{2 *}$, Fujio TSUMORI ${ }^{2}$, Toshiko OSADA ${ }^{2}$ and Hideshi MIURA ${ }^{2}$ \\ ${ }^{1}$ Dept. Mechanical Engineering, Graduate School of Kyushu University, 744 Motooka, Nishi-ku, Fukuoka 819-0395, Japan. \\ ${ }^{2}$ Dept. Mechanical Engineering, Kyushu University, 744 Motooka, Nishi-ku, Fukuoka 819-0395, Japan.
}

Received December 1, 2015; Revised January 25, 2016; Accepted January 30, 2016

\begin{abstract}
As Ni-based superalloy has poor workability, direct laser forming (DLF) would be a powerful tool for fabricating the complex shaped Ni-based superalloy parts. We focused on the microstructure of the parts produced by DLF, the crystal grains of which grow along the building direction. This anisotropic microstructure is one of the major features of the parts produced by DLF, and which may cause anisotropic mechanical properties.

In this work, the optimum laser-forming conditions such as laser power, laser scan speed, and powder feeding rate were determined by evaluating the density of the produced parts. Three types of tensile test pieces and two types of fatigue test pieces were fabricated in different building direction. They had higher ultimate tensile strength than that of JIS standards in wrought materials. However, their elongation was lower than that of JIS standards, and also the dispersion of elongation was large. On the other hand, fatigue limit was a little lower than the standard value. It was confirmed that the mechanical properties of Ni-based superalloy parts produced by DLF were different by a difference in building direction.
\end{abstract}

\section{KEY WORDS}

direct laser forming (DLF), Ni-base superalloy, building direction, mechanical properties, anisotropy

\section{Introduction}

Recently, high efficiency for gas turbine is required from the point of view of energy saving and environmental problem. As Ni-base superalloys have high performance in strength, corrosion resistance, heat resistance and creep resistance, they have been used for various parts used at high temperatures, such as industrial turbine, aircraft jet engine and so on. Inconel 718 is one of the most popular Ni-based superalloys, and it has been mainly used as a material for gas turbine parts. However, Inconel 718 shows poor workability same as other Ni-base alloys. For example, tool wear has become a serious problem during machining ${ }^{1)}$. To overcome those problems, we focused on the direct laser forming (DLF), which is one of additive manufacturing technology and a candidate process for fabricating the complex parts with less-machinable metal materials. The DLF parts are fabricated by repeating the following process, "feeding a layer of metal powder", and "melting by laser and solidification". The DLF process has high performance and is cost-effective for producing near net shape parts with complex shapes in not only outer but also inner structures. In addition, DLF is possible to form a shape based on 3D-CAD data without a mold. These characteristics are suitable for producing the

\footnotetext{
* Corresponding author, E-mail: kudo.kentaro.801@m.kyushu-u.ac.jp
}

complex parts such as turbine blade and engine parts with Inconel 718.

The typical microstructures of DLF Inconel 718 superalloy show the columnar dendrites structure growing along the building direction. After heat treatment at high temperature of over $1100{ }^{\circ} \mathrm{C}$, the columnar dendrites structure transform to uneven distributed equiaxed grains after the recrystallization. In case, there was variance from 5 to $6 \%$ in the strength of test pieces fabricated between in the $\mathrm{x}$-axis orientation which is parallel direction to the laser scanning layer and the z-axis orientation which is parallel to the building direction, as a consequence of the orientation of the columnar $\gamma$ " phase architecture ${ }^{2-4)}$.

In the case of Ti-6Al-4V parts fabricated by DLF, several papers also reported that there was anisotropy of tensile properties ${ }^{5-7)}$.

The goal of this study is to understand the mechanical properties of the Ni-base superalloy parts produced by DLF. By performing tensile test and rotary bending fatigue test, mechanical properties were investigated and the results are discussed in term of difference in building direction.

\section{Experimental procedure}

2.1 Powder and forming condition

Inconel 718 powder produced by gas atomization method (Sanyo special steel Co., Ltd.) was used in this study. Fig. 1 shows the 


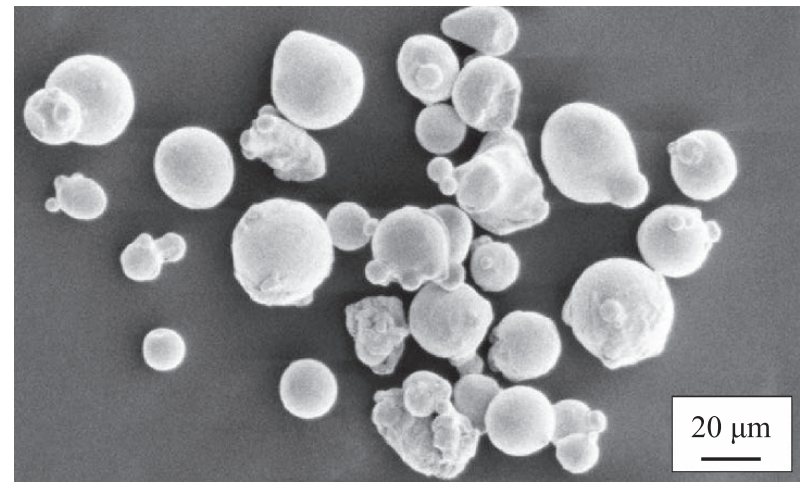

Fig. 1 SEM image of Inconel 718 powder.

Table 1 Chemical composition of powder (mass \%).

\begin{tabular}{ccccccccc}
\hline $\mathrm{Ni}$ & $\mathrm{Cr}$ & $\mathrm{Nb}$ & $\mathrm{Mo}$ & $\mathrm{Ti}$ & $\mathrm{Al}$ & $\mathrm{C}$ & $\mathrm{O}$ & $\mathrm{Fe}$ \\
\hline 52.6 & 19.1 & 5.10 & 3.06 & 0.87 & 0.61 & 0.046 & 0.023 & $\mathrm{Bal}$ \\
\hline
\end{tabular}

Table 2 Laser forming condition.

\begin{tabular}{cc}
\hline Laser power & $280 \mathrm{~W}$ \\
Scan speed & $150 \mathrm{~mm} / \mathrm{s}$ \\
Scan pitch & $0.1 \mathrm{~mm}$ \\
Spot diameter & $50 \mu \mathrm{m}$ \\
Building layer thickness & $80 \mu \mathrm{m}$ \\
Atmosphere & Ar flow $(600 \mathrm{~Pa})$ \\
\hline
\end{tabular}

SEM image of the raw powder, and Table 1 shows the chemical composition. The median diameter (D50) of the raw powder from the laser diffraction particle size analysis was $28.6 \mu \mathrm{m}$. The Inconel 718

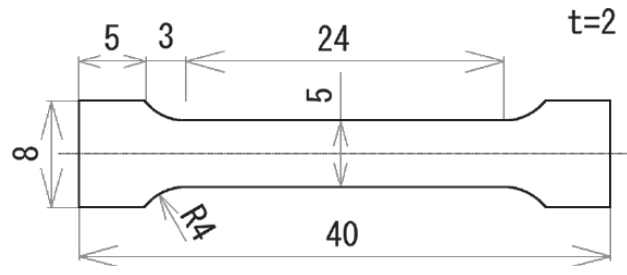

(a) Tensile test piece

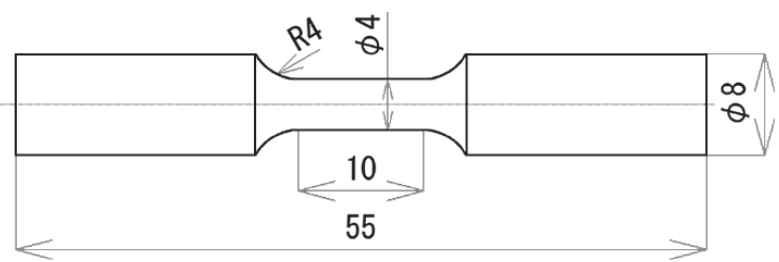

(b) Rotary bending fatigue test piece

Fig. 2 Dimension of tensile test piece and rotary bending fatigue test piece $(\mathrm{mm})$.

powder was thinly fed by a blade, and laser beam was scanned on the powder layer subsequently. Yttrium fiber laser with continuouswave oscillation was used. Forming condition is shown in Table 2. Since all specimens were fabricated in a chamber with a glass window, through which laser beam was transmitted. Atmosphere was argon gas flowing at a pressure of $600 \mathrm{~Pa}$ during the forming.

\subsection{Test pieces}

Fig. 2 shows the dimension of tensile test piece and rotary bending fatigue test piece. The dimension of the tensile and rotary bending fatigue test pieces met Japanese industrial standards, JIS Z 2201 and JIS Z 2274, respectively. Fig. 3 shows the schematic image

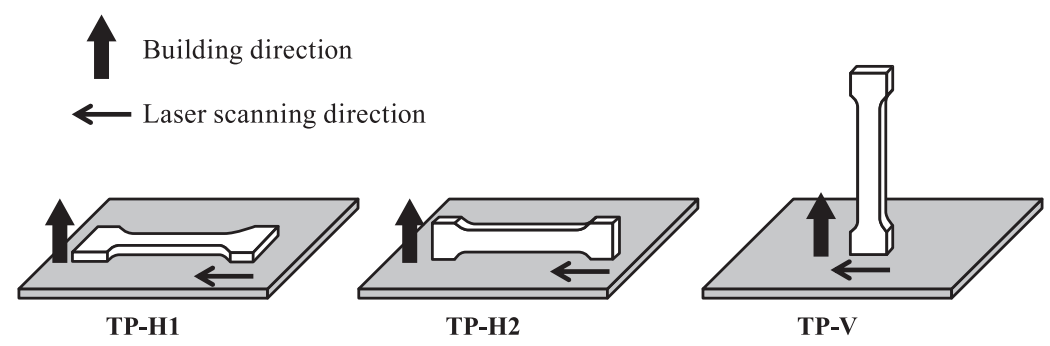

(a) Tensile test piece

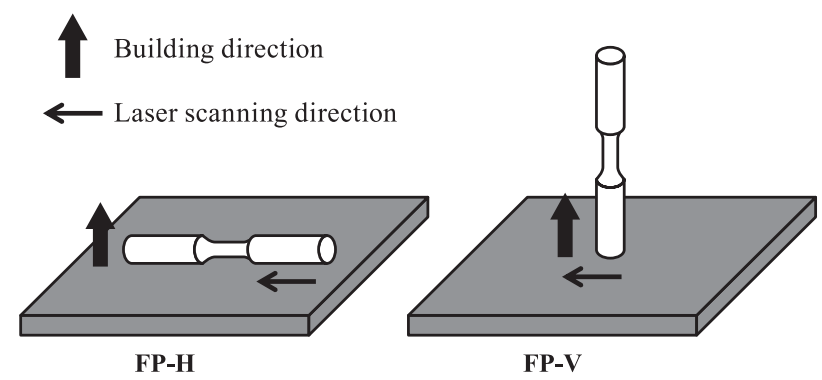

(b) Rotary bending fatigue test piece

Fig. 3 Image of the laser scanning direction and the building direction each test piece. 
during forming the test pieces by changing the building direction. Test piece was cut out from rectangular or cylindrical block. In this paper, tensile test piece are defined as TP-H1, TP-H2, TP-V and rotary bending fatigue test pieces are defined as FP-H, FP-V as shown in the Fig. 3. The name of TP corresponds to Tensile test Piece, and FP means Fatigue test Piece. The notation -H means that long axis direction of test piece is horizontal to substrate surface, and $-\mathrm{V}$ means vertical direction.

Inconel 718 is generally used after aging heat treatment to precipitate the $\gamma$ ' phase $\left(\mathrm{Ni}_{3} \mathrm{Al}, \mathrm{Ni}_{3} \mathrm{Ti}\right)$ and the $\gamma$ " phase $\left(\mathrm{Ni}_{3} \mathrm{Nb}\right)$, which strengthen the material at a high temperature. All laser-formed specimens were aged at $720{ }^{\circ} \mathrm{C}$ for 8 hour in argon, and cooled to $620^{\circ} \mathrm{C}$, then aged at $620^{\circ} \mathrm{C}$ for 8 hours in argon.

\subsection{Tensile and rotary bending fatigue tests}

Tensile test was performed at room temperature under the traverse speed of $1 \mathrm{~mm} / \mathrm{min}$. The elongation was measured by an extensometer attached to the test piece. Gauge length was $5 \mathrm{~mm}$. The rotating bending fatigue test was performed using Ono-type rotating bending fatigue testing machine (capacity is $14.7 \mathrm{~N} \cdot \mathrm{m}$ ) at room temperature with rotational frequency of $3000 \mathrm{rpm}$. Fatigue limit was defined as the stress at $10^{7}$ times of fatigue testing without breaking.

\section{Results and discussion}

\subsection{Microstructure}

Sound specimens were obtained by DLF, and the relative density of test pieces was over $99 \%$. The etched surface observed by an optical microscope is shown three-dimensionally in Fig. 4. The columnar crystal grains having a width about $10 \mu \mathrm{m}$ were grown along the building direction. Grain growth along the building direction has been reported in the case of using another type powders such as titanium alloy, which is one of the major characteristics of the parts fabricated by using laser or electron beam ${ }^{2-10)}$. Moreover, fiberlike precipitates with a width of a few $\mu \mathrm{m}$ in the crystal grains were observed along the building direction. This microstructure has anisotropy of crystal grain and fine precipitation in the grains, which might lead anisotropic mechanical properties.

\subsection{Tensile test}

Fig. 5 shows the tensile strength and elongation of each test piece. The vertical axis corresponds to the tensile strength, and the horizontal axis to the elongation. In Japanese industrial standard (JIS G 4901), the tensile strength and elongation of Inconel 718 are defined as $1240 \mathrm{MPa}$ or more, and $12 \%$ or more, respectively. The tensile strength of the all DLF test piece was greater than the
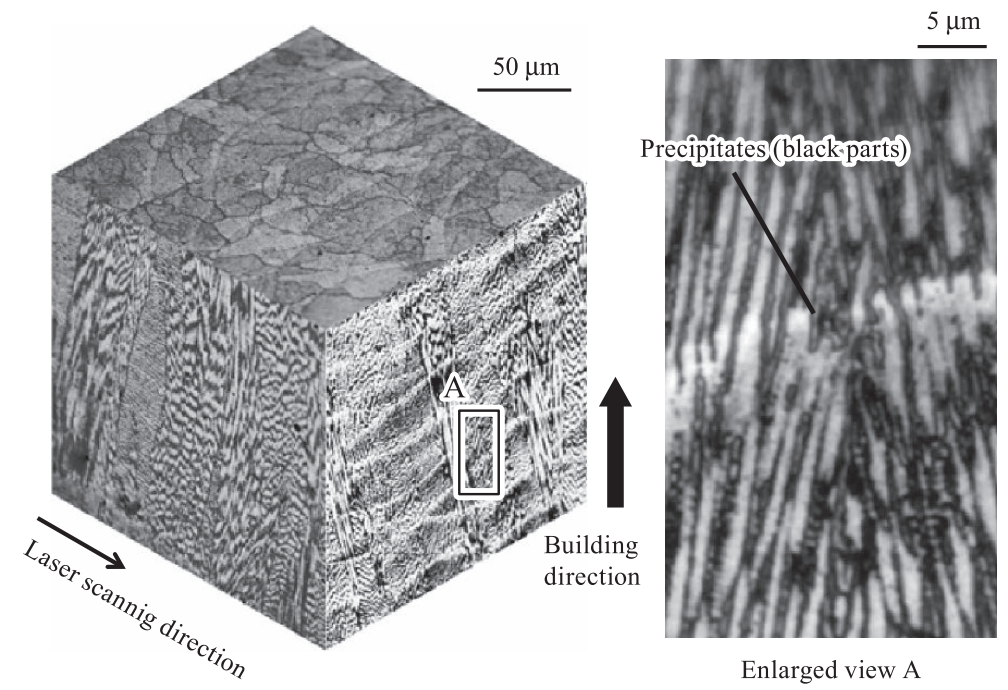

Fig. 4 3D view of optical micrograph in etched condition.

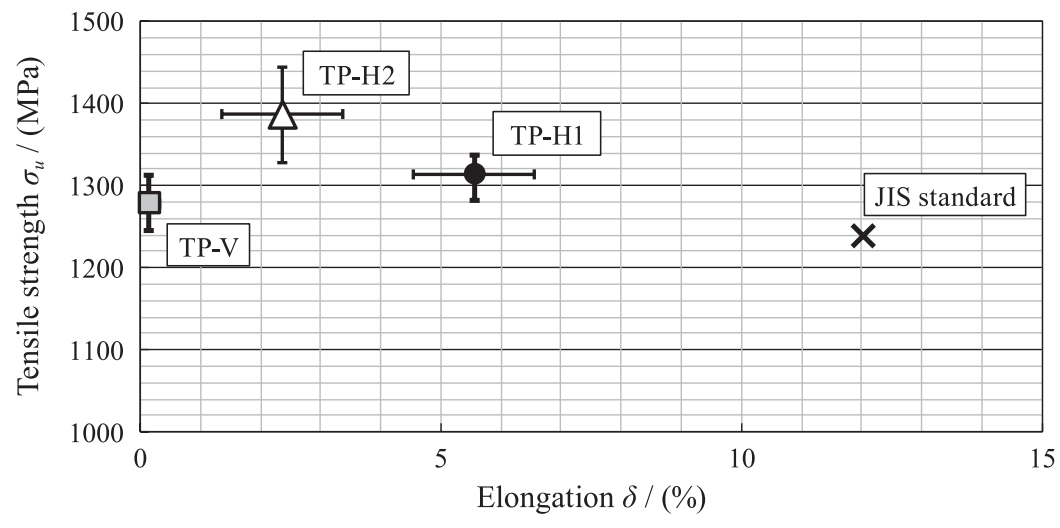

Fig. 5 Result of tensile test. 
standard value. However, the elongation was less than the standard value. In term of the elongation, TP-H1 and TP-H2 showed about $6 \%$, while TP-V3 showed much smaller value, less than $1 \%$.
Fig. 6 shows fractured surface of each test piece. In TP-H1 and TP-H2, the fractured surfaces along the grain growth direction were observed, which show the anisotropy of the crystal grains

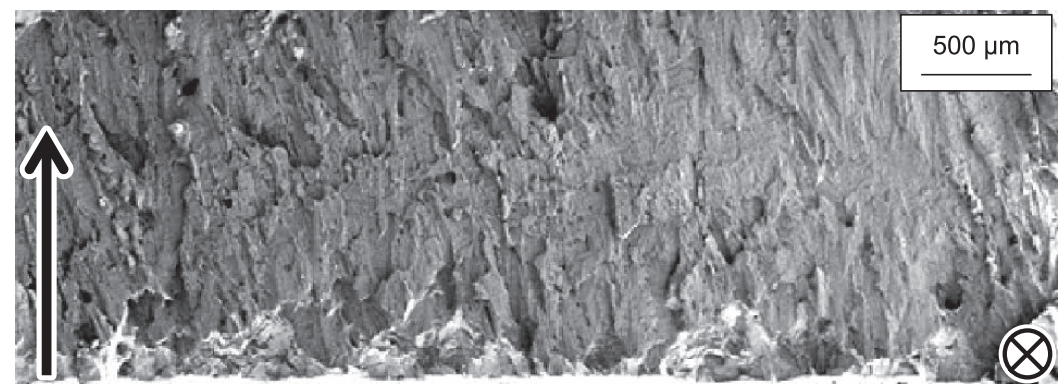

Building direction $\quad$ (a) TP-H1 $\left(\sigma_{u}=1335 \mathrm{MPa}, \delta=6.33 \%\right) \quad$ Laser scannig direction

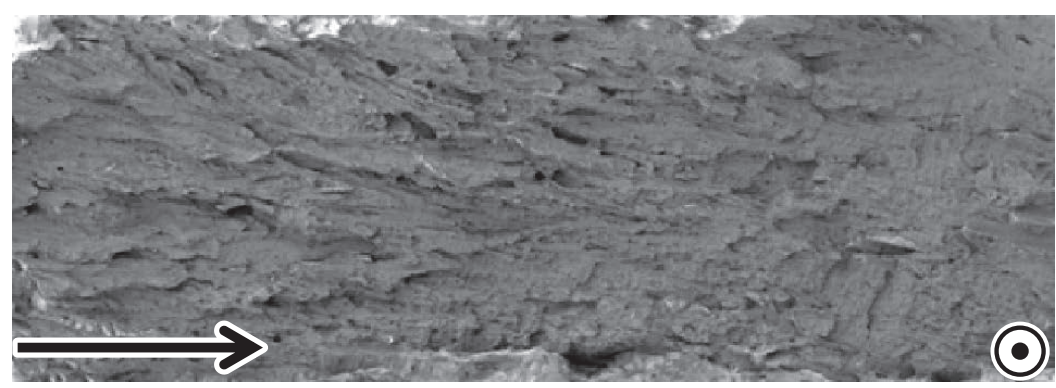

Building direction $\quad$ (b) TP-H2 $\left(\sigma_{u}=1445 \mathrm{MPa}, \delta=4.39 \%\right) \quad$ Laser scannig direction

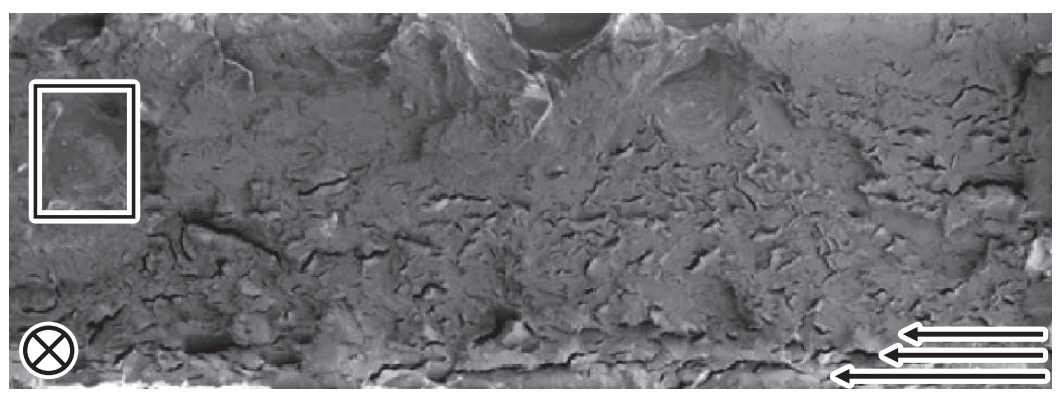

Building direction $\quad$ (c) $\mathrm{TP}-\mathrm{V}\left(\sigma_{u}=1279 \mathrm{MPa}, \delta=0.14 \%\right) \quad$ Laser scannig direction

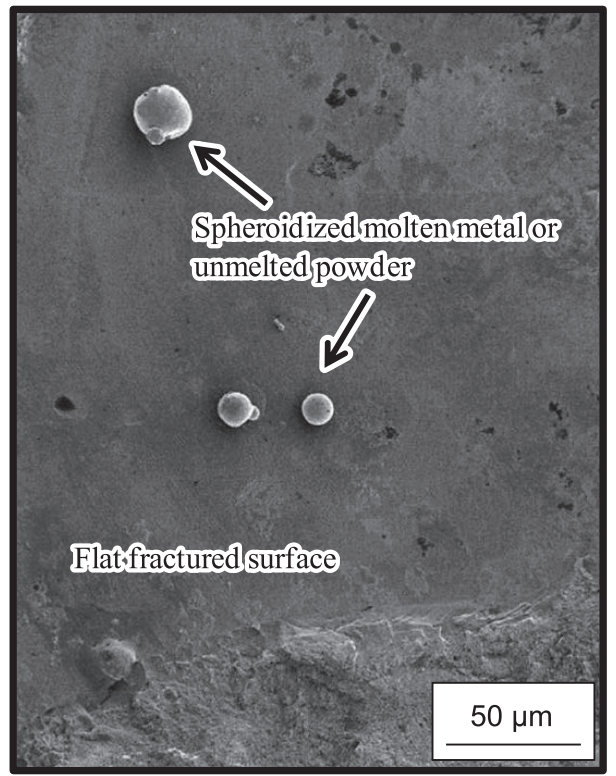

(d) Enlarged view of TP-V

Fig. 6 Observation of fractured surface. 


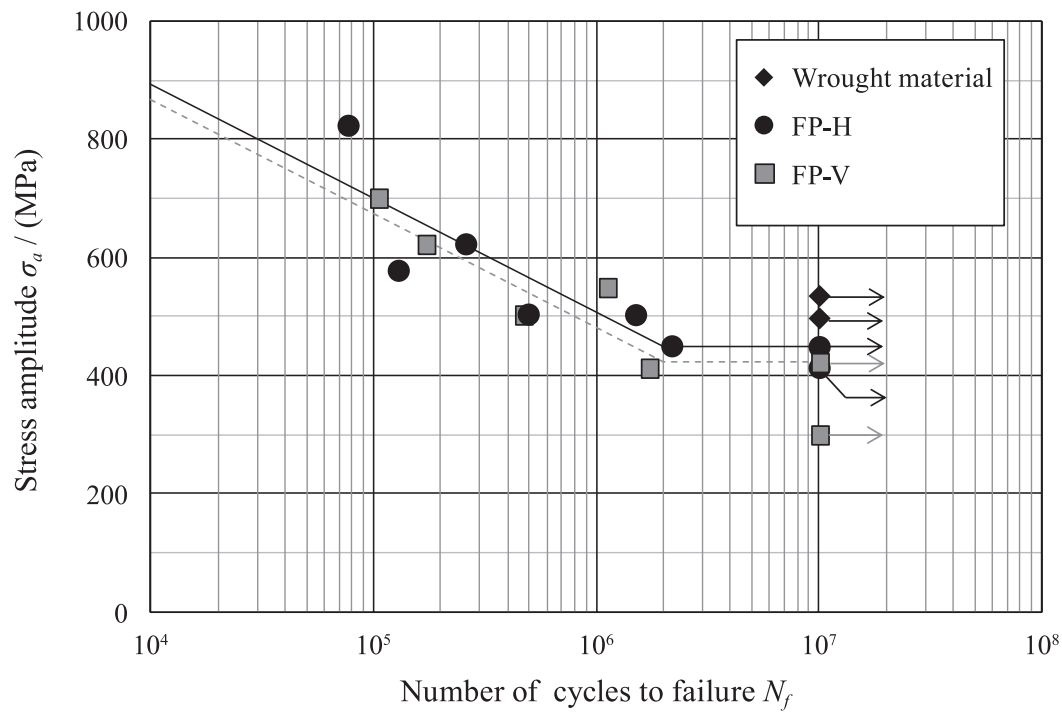

Fig. 7 S-N diagram.

and precipitates. Trace of columnar crystal grains in Fig. 6 (a), there is an angle with respect to the building direction due to the temperature gradient direction after laser scanning ${ }^{5)}$. On the other hand, fractured surface of the TP-V was not along the grain growth direction. In TP-V, fracture form was quite different from those of TP-H1 and TP-H2. As shown in Fig. 6 (d), flat fractured surface is unbonded portions between the layers, and spheroidized molten metal or unmelted powder was observed. It is assumed that the fracture occurred by this interlayer of TP-V3.

\subsection{Rotary bending fatigue test}

Fig. 7 shows the S-N diagram obtained by rotary bending fatigue test. Fatigue limit of FP-H was about $450 \mathrm{MPa}$, and that of FP-V was about $420 \mathrm{MPa}$. Unlike the tensile properties, the anisotropy of fatigue strength due to the difference in the building direction was a little confirmed. Fatigue limit of Inconel 718 of wrought material is reported as about $500 \mathrm{MPa}^{11)}$. Fatigue limit of the DLF test piece was about $80 \%$ of that of the wrought material and there was not so large anisotropy in fatigue strength.

Fig. 8 shows the fractured surface after rotary bending fatigue test. Fig. 8 (a) illustrates an example of fractured surface of FPH. Fig. 8 (b) shows the magnified image in the area of A. Such as the dimples of ductile fracture were not observed, but columnar crystalline architectures along the building direction were observed. While, the equiaxed precipitate morphology along the building direction were observed as shown in Fig. 8 (c). This precipitation morphology corresponds to the precipitations observed in the microstructure of the sample (Fig. 3).

Fig. 8 (d) shows an example of the fractured surface of FP-V. A large inclusion is observed near the upper left corner, and the fracture would start from this inclusion. This phenomenon has not only been reported in the case of using Inconel $718^{12)}$, but also in the cases using Ti-6Al-4 $\mathrm{V}^{13,14)}$, Si -based Al alloy ${ }^{15,16)}$, stainless steel $^{17)}$ and Co alloys ${ }^{18)}$. Furthermore, it has also been reported in the case of using the $\mathrm{LMD}^{19)}$ (laser melting deposition). In crack growth area (area C in Fig. 8 (d)), the magnified image of which is shown in Fig. 8 (e), crater-like pits and protrusions were observed with a diameter of about $1 \mu \mathrm{m}$. These pits and protrusions correspond to cross-section of the fiber-like precipitations. The fracture ended near area D shown in Fig. 8 (b). As shown in Fig. 8 (f), coarse striations perpendicular to the crack growth direction were observed.

FP-H is less susceptible to inclusion than FP-V because the number of building is lower and the area of the layer interface is larger. However, precipitates extended in the building direction are more difficult to suppress the crack growth than that of FP-V because they are parallel to the crack growth direction. Since the precipitates grown in the building direction are perpendicular to the crack growth direction, the crack growth resistance of FP-V is higher than that of FP-H. In other word, crack initiation of the FP-H is slow but crack growth is fast, crack initiation of the FP-V is fast but crack growth is slow.

\section{Conclusion}

For the application of direct laser forming to the Ni-base superalloy, a tensile test piece and rotary bending fatigue test piece were fabricated by using inconel 718 powder and changing the building directions. Then, their mechanical properties were investigated and discussed by observing the fractured surface. The results of this study are summarized as follows;

(1) In all test pieces, the tensile strength was higher than the JIS standard. However, when the building direction is parallel to the loading direction, the elongation was smaller than the standard value, the variation was large. Anisotropy was confirmed from the tensile test results.

(2) From the fractured surface observation of the tensile test pieces, when the building direction was parallel to the load direction, the fractured surface was different from any other forming 


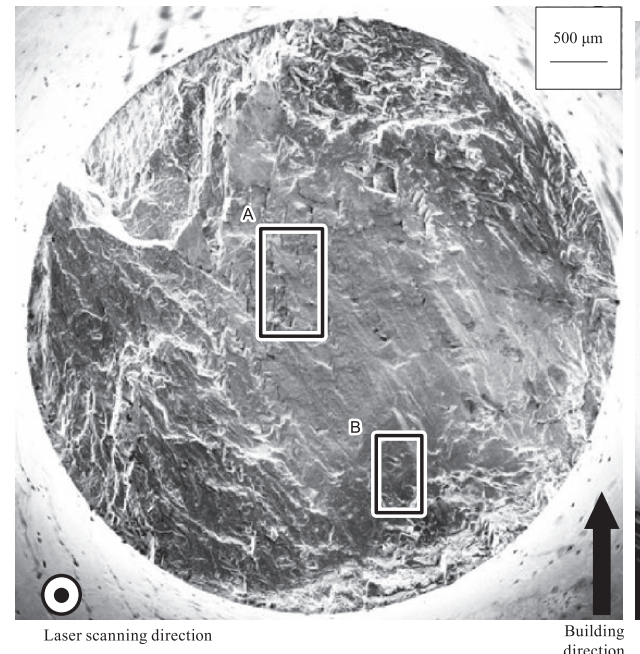

(a) FP-H $\left(\sigma_{a}=450 \mathrm{MPa}, N_{f}=2.2 \times 10^{6}\right)$

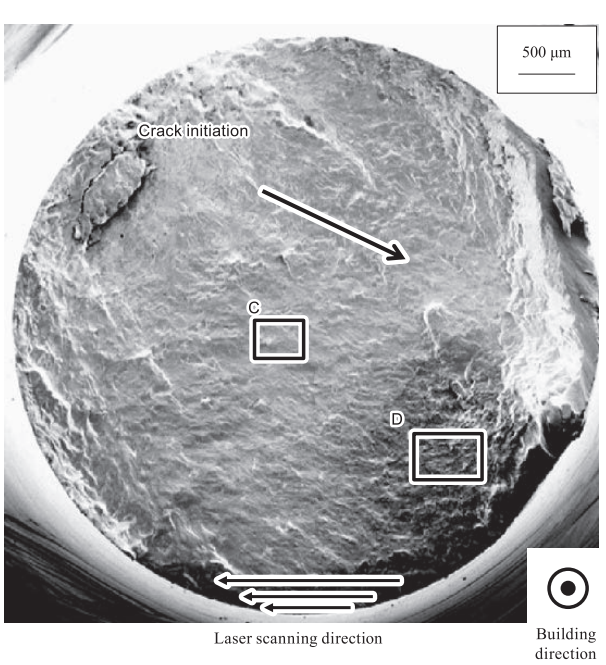

(d) FP-V $\left(\sigma_{a}=413 \mathrm{MPa}, N_{f}=1.7 \times 10^{6}\right)$

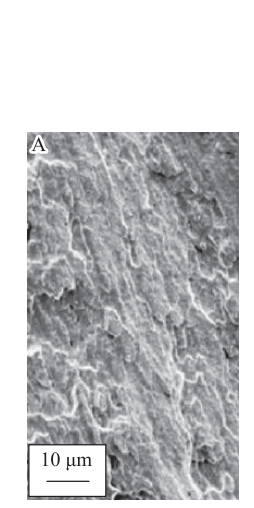

(b) Enlarged view A

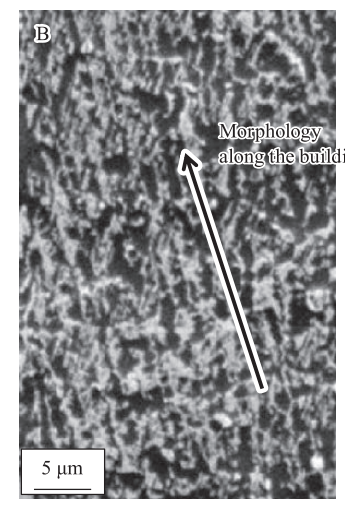

(c) Enlarged view B

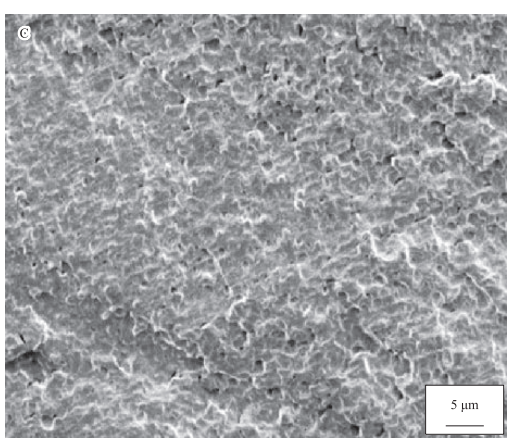

(e) Enlarged view $\mathrm{C}$

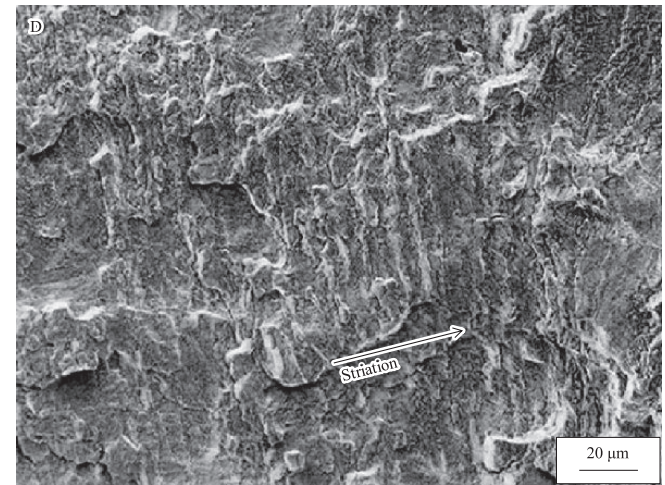

(f) Enlarged view D

Fig. 8 Observation of fractured surface.

condition. In this case, the tensile strength and elongation was very law, which is estimated that the fracture occurs in the unbonded portions between the layers.

(3) Unlike the tensile properties, anisotropy in fatigue strength by differing in the building direction was a little confirmed.

\section{References}

1) K. Itakura, M. Kuroda, et al.: "Wear Mechanism of Coated Cemented Carbide Tool in Cutting of Super Heat Resisting Alloy Inconel 718", The Japan Society for Precision Engineering,
65 (1999) 976-981.

2) K. N. Amato, S. M. Gaytan, et al.: "Microstructures and mechanical behavior of Inconel 718 fabricated by selective laser melting", Acta Materialia, 60 (2012) 2229-2239.

3) L. E. Murr, E. Martinez, et al.: "Fabrication of Metal and Alloy Components by Additive Manufacturing: Examples of 3D Materials Science", Journal of Materials Research and Technology, 1 (2012) 42-54.

4) F. Liu, X. Lin, et al.: "Microstructure and residual stress of laser rapid formed Inconel 718 nickel-base superalloy”, Optics 
\&Laser Technology, 43 (2011) 208-213.

5) F. Liu, X. Lin, et al.: "The effect of laser scanning path on microstructures and mechanical properties of laser solid formed nickel-base superalloy Inconel 718", Journal of Alloys and Compounds, 509 (2011) 4505-4509.

6) C. Qiu, N. J. E. Adkins, M. M. Attallah: "Microstructure and tensile properties of selectively laser-melted and of HIPed laser-melted Ti-6Al-4V", Materials Science \& Engineering A, 578 (2013) 230-239.

7) V. Cain, L. Thijs, et al.: "Crack propagation and fracture toughness of Ti6Al4V alloy produced by selective laser melting”, Additive Manufacturing, 5 (2015) 68-76.

8) M. W. Wu, P. H. Lai, et al.: "Anisotropy in the impact toughness of selective laser melted Ti-6Al-4V alloy", Materials Science and Engineering: A, 650 (2016) 295-299.

9) K. Kunze, T. Etter, et al.: "Texture, anisotropy in microstructure and mechanical properties of IN738LC alloy processed by selective laser melting (SLM)", Materials Science \& Engineering A, 620 (2015) 213-222.

10) T. Boegelein, S. N. Dryepondt, et al.: "Mechanical response and deformation mechanisms of ferritic oxide dispersion strengthened steel structures produced by selective laser melting", Acta Materialia, 87 (2015) 201-215.

11) N. Kawagoishi, S. Yoshimi, et al.: "Effect of Aging Condition on Fatigue Properties of Ni-Base Super Alloy Inconel 718 at Room Temperature", Transactions of the Japan Society of Mechanical Engineers, Series A, 74 (2008) 994-999.

12) Q. Jia, D. Gu: "Selective laser melting additive manufacturing of Inconel 718 superalloy parts: Densification, microstructure and properties", Journal of Alloys and Compounds, 585 (2014) 713-721.

13) C. Qiu, C. Panwisawas, et al.: "On the role of melt flow into the surface structure and porosity development during selective laser melting”, Acta Materialia, 96 (2015) 72-79.

14) H. Gong, K. Rafi, et al.: "Analysis of defect generation in Ti-6Al$4 \mathrm{~V}$ parts made using powder bed fusion additive manufacturing processes", Additive Manufacturing, 1-4 (2014) 87-98.

15) N. T. Aboulkhair, N. M. Everitta, I. Ashcroft, C. Tuck: "Reducing porosity in AlSi10Mg parts processed by selective laser melting", Additive Manufacturing, 1-4 (2014) 77-86.

16) K. Kempen, L. Thijs, J. V. Humbeeck, J. P. Krutha: "Mechanical properties of AlSi10Mg produced by Selective Laser Melting", Physics Procedia, 39 (2012) 439-446.

17) B. Zhang, L. Dembinski, C. Coddet: "The study of the laser parameters and environment variables effecton mechanical properties of high compact parts elaborated by selective laser melting $316 \mathrm{~L}$ powder", Materials Science \& Engineering A, 584 (2013) 21-31.

18) A. Takaichi, T. Nakamoto, N. Joko, et al.: "Microstructures and mechanical properties of Co-29Cr-6Mo alloy fabricated by selective laser melting process for dental applications", journal of the mechanical behavior of biomedical materials, 21 (2013) 67-76.

19) Y. Zhu, X. Tian, J. Li, H. Wang: "The anisotropy of laser melting deposition additive manufacturing Ti-6.5Al-3.5Mo-1.5Zr-0.3Si titanium alloy", Materials and Design, 67 (2015) 538-542. 